\title{
Camptodactyly syndrome, Guadalajara type 2
}

INSERM

\section{Source}

INSERM. (1999). Orphanet: an online rare disease and orphan drug data base. Camptodactyly syndrome, Guadalajara type 2. ORPHA:1326

Camptodactyly syndrome, Guadalajara type 2 is an extremely rare multiple congenital anomaly syndrome characterized by distinctive intrauterine growth retardation, skeletal dysplasia with multiple malformations including camptodactyly of all fingers, bilateral hallux valgus, short second, fourth and fifth toes, hypoplastic patella, microcephaly, lowset ears, short neck, cuboid-shaped vertebral bodies, pectus excavatum, hip dislocation, and hypoplastic pubic region and genitalia. Camptodactyly syndrome, Guadalajara type 2 has been described in two sisters and is most likely transmitted in an autosomal recessive manner. There have been no further descriptions in the literature since 1985. 